\title{
The Application of Health Pedagogy in the Context of the Formation of Physical Education among Schoolchildren
}

\author{
${ }^{1}$ Svitlana Kryshtanovych ${ }^{*}$, ${ }^{2}$ Mykola Balukh, ${ }^{2}$ Galyna Buchkivska, ${ }^{3}$ Nataliia \\ Chubinska ${ }^{(D)}{ }^{4}$ Daria Ilina \\ ${ }^{1}$ Department of Pedagogy and Psychology, State University of Physical Culture named after Ivan \\ Bobersky, Lviv, Ukraine. ${ }^{2}$ Humanitarian Faculty, Khmelnytskyi Humanitarian-Pedagogical Academy, \\ Khmelnytskyi, Ukraine. ${ }^{3}$ Pedagogical Sciences, Lviv Polytechnic National University, Lviv, Ukraine. \\ ${ }^{4}$ Department of Primary and Professional Education, H.S. Skovoroda Kharkiv National Pedagogical \\ University, Kyiv, Ukraine.
}

Submitted 01 April 2021; Accepted in final form 26 May 2021.

\begin{abstract}
Background. At the present stage of the development of society, one of the priority tasks of the state is to improve the system of physical education for schoolchildren. Recently, the problem of reforming the school system of physical education has become extremely urgent. Objectives. The purpose of our study is to form a model for implementing the health care system for the formation of sports education among schoolchildren. Methods. The basis of our methodology is the functional modeling system IDEF0, which allows us to form a model according to the goal set in the study. Results. Our research has brought an original result, which consists in the formation of a model for implementing a health care system for the formation of physical education among schoolchildren. Conclusion. Further research will be aimed at analyzing the attitude of physical culture teachers to innovations that are declared in the curriculum based on the principle of variability, as well as the willingness of specialists to work according to modular programs.
\end{abstract}

\section{KEYWORDS: Physical Education, Health, Modern Sports, Pedagogy, Schoolchildren.}

\section{INTRODUCTION}

The end of the 20th century and the beginning of the 21 st century is characterized by the deepening of crisis phenomena in many areas of world development. This situation poses challenges for humanity to form a new worldview, substantiate new values, moral and ethical criteria, and correct common goals and priorities.

The concept of sustainable development is aimed at such changes. Sustainable development is a general concept of the need to balance meeting the modern needs of humankind and protecting the interests of future generations, including their needs for a safe and healthy environment. Sustainable development as defined by the UN is the development of society, it allows meeting the needs of the present generation, and without harming the possibilities of future generations to meet their own needs. In the short term, the strategic goal of Ukraine's sustainable development should be to overcome the economic and structural crisis developed during the transition to a market economy and a democratic civil society (1-4). To achieve sustainable development, an integrated approach is required, providing for

*. Corresponding Author:

Svitlana Kryshtanovych, Ph.D

E-mail: skrischtanovich@gmail.com 
coordinated work in several areas. Environmental safety as the strategic goal is the preservation and restoration of natural ecosystems, stabilization and improvement of the quality of the environment, reduction of emissions of harmful substances, etc.

Economic stability: the goal is to create a socially and environmentally efficient economy that ensures a decent standard of living for citizens and competitiveness of products. An important target should be the provision of economic development mainly in the already developed territories.

Social well-being: the main goal is to increase the average life expectancy of the population, family planning and rationalization of personal consumption, improvement of the human environment, development of his social activity, ensuring equal opportunities in obtaining medical care, social protection of vulnerable groups of the population (5-11).

The overwhelming majority of international organizations of the UN system have included in their activities a significant environmental component focused on the transition to sustainable development. World Bank experts have defined sustainable development as managing a set (portfolio) of assets aimed at preserving and expanding the opportunities available to people. Assets include not only traditionally measured physical capital, but also natural and human capital. To be sustainable, development must provide growth - or at least a decrease - over time for these assets (and not just economic growth!). The current approaches to measuring wealth accumulation do not consider the depletion and degradation of natural resources, such as forests and oil fields, on the one hand, and investment in people - one of the most valuable assets of any country. In recent years, politicians, doctors, researchers, teachers state the fact that the requirement to fulfill one of the main tasks of the state educational program - the formation and preservation of the health of children and adolescents - conflicts with the existing signs of socio-economic and environmental crises, in particular a sharp deterioration in the health of the younger generation (12-23).

The problem of health saving has been taking on a global scale in recent decades. Already today it ranks seventh among the threats of a planetary scale (the threat of a World War, environmental disasters, inequality of economic relations in various countries of the world, demographic threat, lack of natural resources, the consequences of scientific and technological progress. The problem of human health preservation). In addition, the state of health of a nation is an indicator of the spiritual, socio-economic and medico-biological level of well-being of a civilized country. All this determines the actualization of the scientific search for the study and development of the problem of protecting and preserving the health of schoolchildren in general education institutions.

The main goal of the study is to find the main ways of introducing health pedagogy into the process of physical education of schoolchildren, for this it is important to use an appropriate modeling technique that will functionally demonstrate these areas.

The information that was used in the process of building a functional model was taken as a result of scientific cooperation with teachers of Ukrainian educational institutions, in addition, for practical testing of the model, this model was tested by educational institutions in Ukraine.

\section{MATERIALS AND METHODS}

Sport as a socio-economic phenomenon contributes to the achievement of the strategic goals of the European Union - solidarity and prosperity. It is associated with the concepts of peace, tolerance, mutual understanding and education in line with European ideals and values. From a social point of view, physical education and sports have a significant impact on the development of a young person from an early age in a wide variety of forms, not only from academic performance and future employment, but also fostering the concept of fairness, teamwork skills, communication and conflict resolution skills. Sport can be used as a means of increasing the level of concentration of schoolchildren, improving their behavior and general attitude towards learning.

For our modeling, information was taken as a result of a theoretical and analytical study of scientific sources, including for a practical understanding of the problem, the activities of two educational institutions in Ukraine were analyzed. In these educational institutions, the professional activities of teachers and schoolchildren in the field of physical education and health preservation were analyzed.

To form a model for the implementation of the health care system for the formation of physical education among schoolchildren, we use the IDEF0 functional modeling system. As with 
creating any other functional model, the IDEF0 model must have the appropriate raw data, which serves as the basic platform for creating our model.

An example of the application of a functional model can be considered the work of Ukrainian scientists (24), who applied the methodology of functional modeling in the process of increasing students' creativity.

The key structural components of the initial data for the formation of the model for the implementation of the health care system of the formation of physical education among schoolchildren are shown in Table 1.

First, in order to achieve our task, we need to build a high-level context diagram A-0 of the IDEF0 functional model for implementing the health care system for the formation of physical education among schoolchildren. So, let's build a tree of nodes, a list of functions and objects with explanations will become the initial basis for their creation (Figure 1). Each block in the IDEF0 functional model diagrams implements the process of converting input to outputs through certain mechanisms. For our task, it is enough just to talk about the transformation of information objects and flows.

\section{RESULTS}

Integrally, the entire system we simulate is denoted by the A-0 block. In accordance to this, all inputs, outputs, controls and mechanisms will be connected to the block by limit arrows and codes in Figure 2.

Figure 3 shows the decomposition of the first level of the context diagram of the functional model IDEF0 for implementing the health care system for the formation of physical education among schoolchildren.

Table 1. The Main Components of the Functional Model IDEF0 for the Implementation of the Health Care System for the Formation of Sports Education among Schoolchildren

\begin{tabular}{|c|c|}
\hline Component & Meaning \\
\hline The goal of modeling & $\begin{array}{l}\text { To develop a functional model IDEF0 for the implementation of the health care system for the } \\
\text { formation of sports education among schoolchildren }\end{array}$ \\
\hline Subject & Employees of physical education; \\
\hline Object & Schoolchildren and persons interested in improving the process of their physical education \\
\hline $\begin{array}{l}\text { Functional model } \\
\text { context }\end{array}$ & a list of functions and objects of diagrams of the IDEF0 functional model; \\
\hline Simulation software & An application program for constructing vector diagrams \\
\hline
\end{tabular}

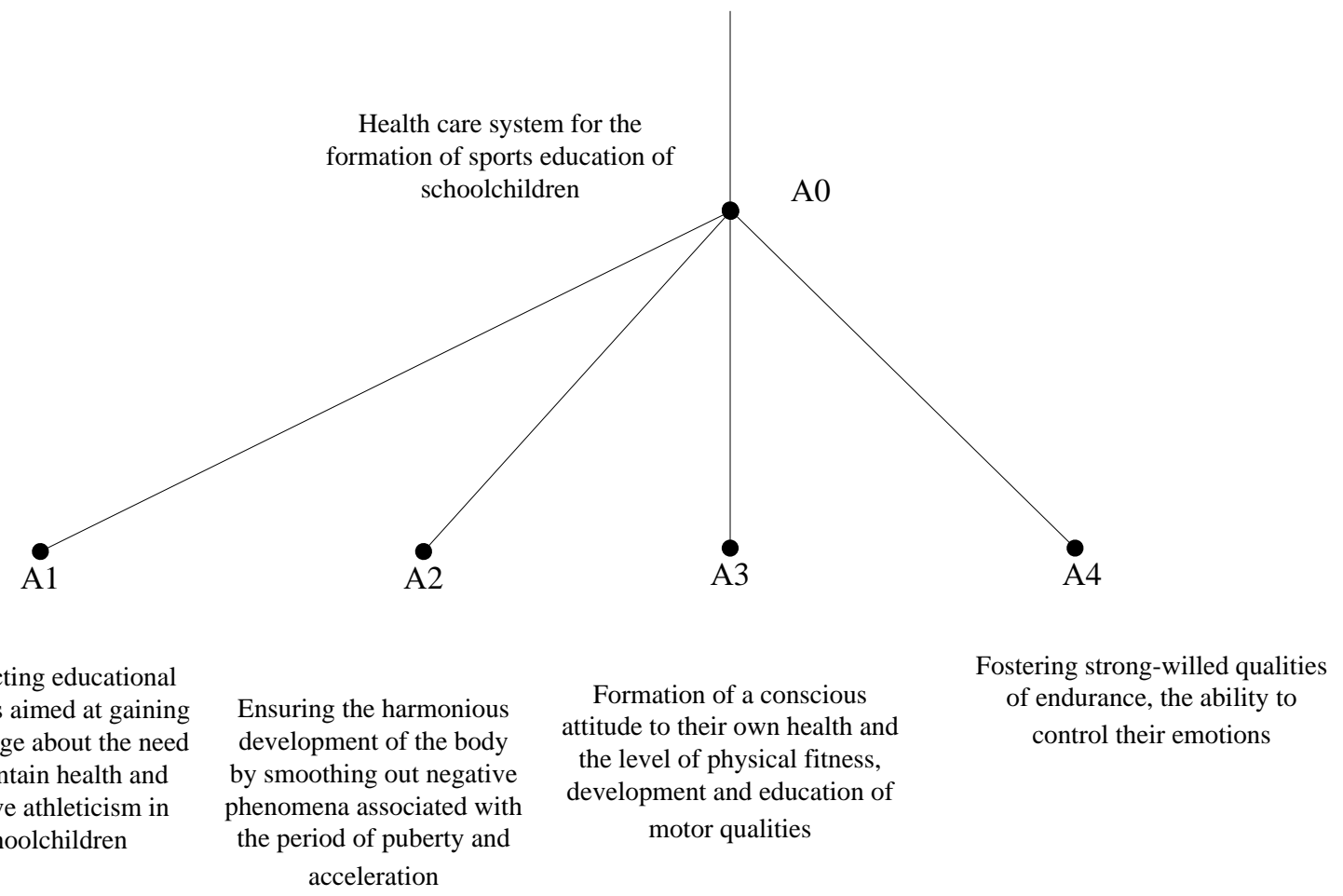

Conducting educational activities aimed at gaining knowledge about the need to maintain health and improve athleticism in schoolchildren
Ensuring the harmonious development of the body by smoothing out negative phenomena associated with acceleration

$$
\begin{aligned}
& \text { Formation of a conscious } \\
& \text { itude to their own health and } \\
& \text { he level of physical fitness, } \\
& \text { evelopment and education of } \\
& \text { motor qualities }
\end{aligned}
$$

Figure 1. Hierarchy of Blocks of the Functional Model IDEFo for Implementing the Health Care System for the Formation of Physical Education among Schoolchildren. 


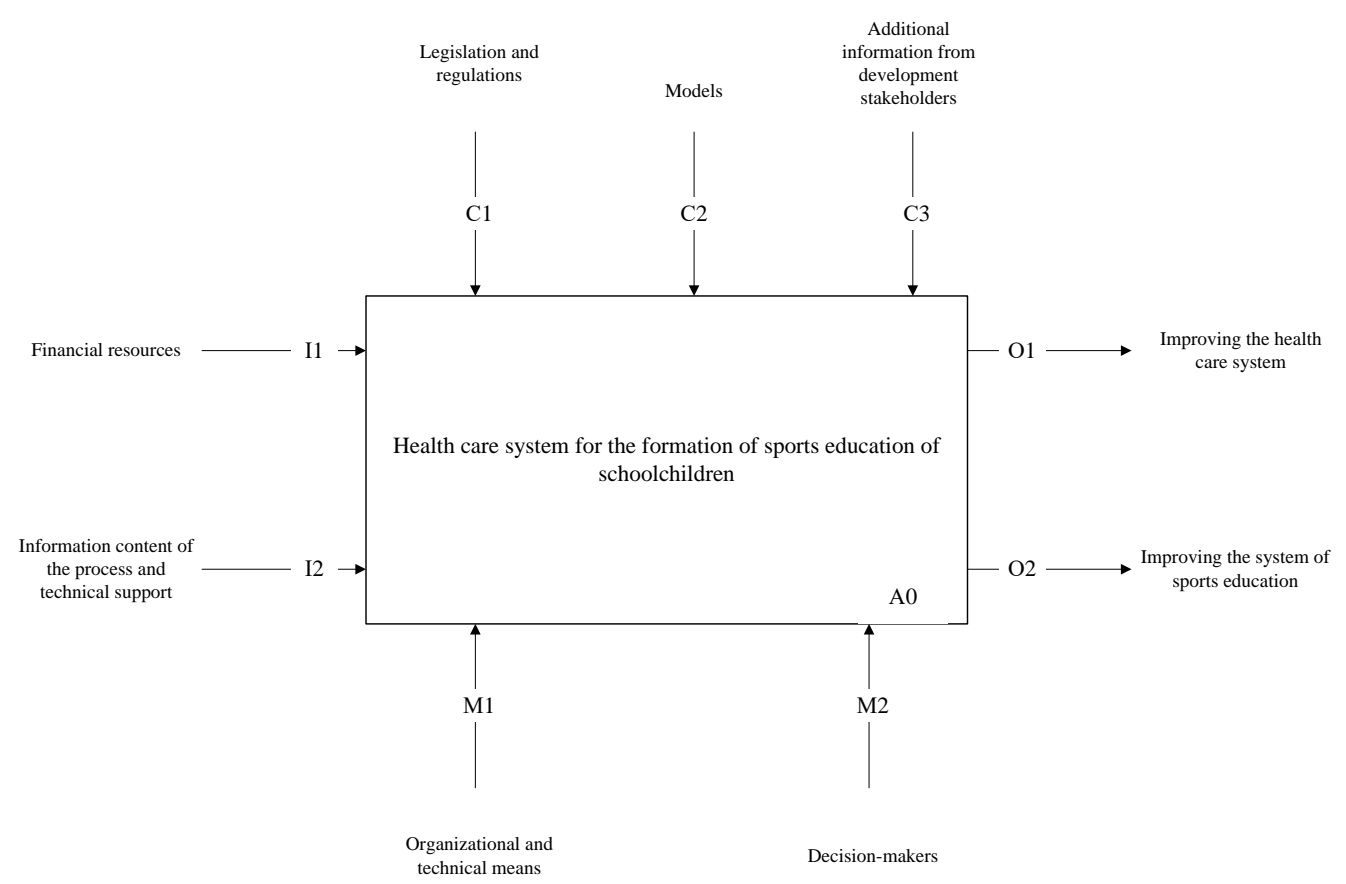

Figure 2. Complex Model Diagram IDEF0 for Implementing the Health Care System for the Formation of Physical Education among Schoolchildren.

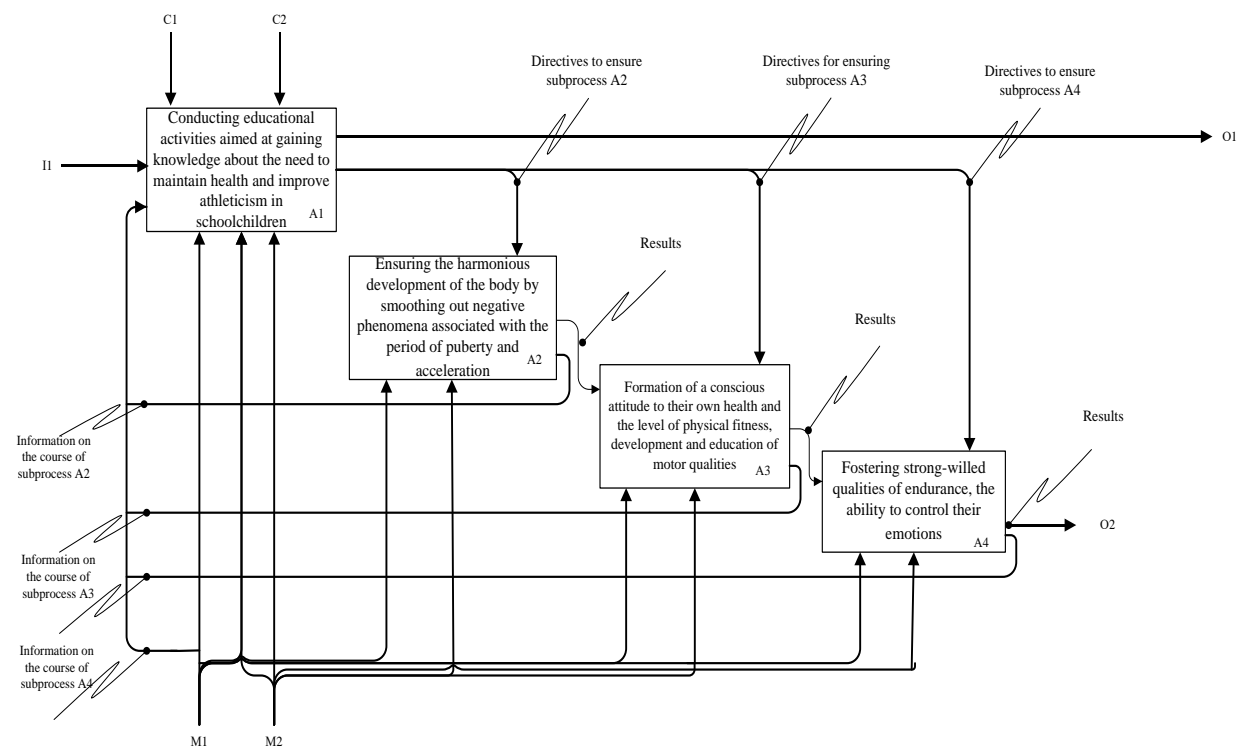

Figure 3. Decomposition of the First Level of the Context Diagram of the IDEFo Model for Implementing the Health Care System for the Formation of Physical Education among Schoolchildren.

As can be seen from Fig. 3, the decomposition of the first level of the context diagram of the functional model IDEF0 for implementing the health care system for the formation of physical education among schoolchildren comprises five blocks that reflect the fulfillment of our goal.

A1- Conducting educational activities aimed at gaining knowledge about the need to maintain health and improve athleticism in schoolchildren. 
Here we include: arming schoolchildren with applied knowledge necessary for implementing a healthy lifestyle and optimal motor regime, conducting independent physical exercises, adhering to the rules of self-control and preventing injuries. Teaching the technique of the main movements performed in conditions of various complexity.

A2 - Ensuring the harmonious development of the body by smoothing out negative phenomena associated with the period of puberty and acceleration. These tasks can be planned: Hardening of the body, increasing its general resistance to factors of physical fatigue, temperature effects of the external environment, etc. Ensuring optimal development of motor qualities. It is necessary for children of secondary school age to develop speed-strength qualities, dexterity, flexibility (mobility in the joints), balance, endurance to short-term static efforts and moderate physical exertion. At the beginning and in the middle of this age period, the greatest attention should be paid to the development of speed, at the end of the period of development of speed-strength qualities. Strengthening the skills of correct posture in various conditions of motor activity, correction of the constitutional features (muscle volumes, body weight, etc.).

A3 - the formation of a conscious attitude to their own health and the level of physical fitness, development and education of motor qualities.

A4 - fostering strong-willed qualities of endurance, the ability to control their emotions.

\section{DISCUSSION}

Discussing the results of our research, we can argue that the originality lies in the fact that we mathematically formed a context diagram of the IDEF0 model for the implementation of the health care system for the formation of physical education among schoolchildren.

Comparing our results with similar studies, we note that for example, Buck, M., Lund, J., Harrison, J. \& Blakemore Cook, C. (8) presented a more textual, step-by-step strategy when we graphically depicted our vision in this issue.

If we compare the similar work of the past years by lfrey, L., \& Burke, G., \& O'Connor, J., \& Hall (25), then the system of maintaining health in the process is presented in the form of chaotic recommendations. While our model is represented by a system of recommendations that can be adapted to the conditions of each individual educational institution.
Another example, Doherty, A, Taylor, T. (15) propose certain ways to improve the physical education of young people, however, they do not offer such a model as ours, which can be known as a convenient graphic assistant for teachers in the field of physical education.

In the work of Skinner (26), health pedagogy is described in the context of general rules at the level of the system of educational institutions in the region. In our opinion, an important aspect of the successful implementation of such principles is the adaptation of each event in accordance with the realities of the educational institution.

Consequently, we can talk about a number of advantages of the context diagram of the IDEF0 model for the implementation of the health care system for the formation of physical education among schoolchildren that we have developed: completeness of the description of this issue; the complexity of the decomposition, which was presented in the article; opportunities for its correction and improvement depending on situations and environment; simplicity of processes.

Thus, the model formed by us and the decomposition constructed will fully help teachers to introduce the health care system into the process of forming physical education. In order to implement the obtained theoretical results, the model we have built is proposed for use by physical education teachers.

For practical testing of this model, we proposed to introduce this model in two educational institutions of Ukraine, one of which has a purely sports direction of educational activity. Physical education teachers were offered to use this model during one academic semester, which lasted six months. The teacher had to apply this model with separately selected classes of students, and in the next, compare the pace of sports learning and health maintenance.

After this model was used by physical education teachers for six months, they could evaluate the effectiveness of the latter in comparison with similar results in classes where this model is not used.

The construction of the model is based on theoretical research of sources and the professional opinion of people who are involved in this field, so this study is not an empirical report.

As a result of expert assessment in the form of interviews, we concluded that the use of this 
model greatly helped teachers in physical education.

\section{CONCLUSION}

Physical education is the main direction of the implementation of physical culture and is an organic part of general education, designed to ensure the development of physical, moralvolitional, mental abilities and professionally applied skills of a person. An unquestioning psychological factor is important in the process of physical education of these categories, which for schoolchildren is the main factor that determines the direction of such education and makes the basis for it. The school should perform various functions: pay significant attention to the upbringing of motor culture, the development of personal and psychophysical qualities, and the introduction of a child to a healthy lifestyle.

To implement the model for the implementation of the health care system for the formation of physical education among schoolchildren, the authors used the functional modeling methodology, within which the decomposition of the first and second levels was built, which is designed to help teachers improve the existing foundations of health pedagogy. For a practical test of this model, we proposed to two educational institutions to implement this model in practice. As a result of feedback from teachers, we can conclude that the model we have built is successful in comparison with traditional forms of educational activity.

Of course, research is not without limits. And first of all, this concerns the fact that the model we have proposed is used exclusively for schoolchildren. In the future, attention should be paid to physical education and health preservation for schoolchildren of higher educational institutions. It also remains open for further research and questions of physical education in the context of post-pandemic and distance learning.

\section{APPLICABLE REMARKS}

- The study offers, unlike other similar ones, the prevailing context diagram of the IDEF0 model for the implementation of the health care system for the formation of physical education among schoolchildren

- Other studies may be devoted to the analysis of the main sports programs for the development of schoolchildren.

- Other studies may include studies of the characteristics of physical education in a covid-19 setting.

\section{ACKNOWLEDGMENTS}

There are no acknowledgements.

\section{CONFLICT OF INTEREST}

The authors declare that there are no conflicts of interest.

\section{REFRENCES}

1. Beamish R. Sport and the logic of capitalism. In H. Cantelon \& R. Gruneau (Eds), Sport, culture and the modern state. Toronto, Canada: University of Toronto Press; 1982.

2. Grant B. Integrating sport into the physical education curriculum in New Zealand secondary schools. Quest. 1992;44(3):304-316. doi: 10.1080/00336297.1992.10484057

3. Grant BC, Pope CC. Retrospection and ruminations on sport and physical education. J Physic Educat New Zealand. 2000;33(2):64-68.

4. Hillary Commission for Sport FaL. Moving through sport: From junior to adult. Wellington, New Zealand: Author1997.

5. Ross B. Press ups, put downs and playing games: The meaning of physical education? Child Issue. 2004;8(1):22-25.

6. Stothart B. Nine strikes and you're out: New Zealand physical education in crisis. J Physic Educat New Zealand. 2005;38:95-102.

7. Bailey R, Kirk D. Introduction. In R. Bailey \& D. Kirk (Eds), The Routledge physical education reader. New York: Routledge; 2009.

8. Buck M, Lund J, Harrison J, Blakemore Cook C. Instructional strategies for secondary physical education. New York: McGraw-Hill; 2007.

9. Fisher A, Reilly JJ, Kelly LA, Montgomery C, Williamson A, Paton JY, et al. Fundamental movement skills and habitual physical activity in young children. Med Sci Sports Exerc. 2005;37(4):684-688. doi: 10.1249/01.mss.0000159138.48107.7d pmid: 15809570

10. Hilbrecht M. Changing perspectives on the work-leisure relationship. Annal Leisure Res. 2007;10(34):368-390. doi: 10.1080/11745398.2007.9686772 
11.Bartsch F, Rulofs B. Intersections of Forced Migration and Gender in Physical Education. Front Sociol. 2020;5:539020. doi: 10.3389/fsoc. 2020.539020 pmid: 33869488

12. Barker D. In defence of white privilege: Physical education teachers' understandings of their work in culturally diverse schools. Sport Educat Soc. 2019;24(2):134-146. doi: $10.1080 / 13573322.2017 .1344123$

13.Benn T, Pfister G. Meeting needs of Muslim girls in school sport: case studies exploring cultural and religious diversity. Eur J Sport Sci. 2013;13(5):567-574. doi: 10.1080/17461391.2012.757808 pmid: 24050475

14. Columna L, Foley J, Lytle R. Physical education teachers' and teacher candidates' attitudes toward cultural pluralism. J Teach Physic Educat. 2010;29(3):295-311. doi: 10.1123/jtpe.29.3.295

15. Doherty A, Taylor T. Sport and physical recreation in the settlement of immigrant youth. Leisure/Loisir. 2007;31(1):27-55. doi: 10.1080/14927713.2007.9651372

16. Elliott D, Hoyle K. An examination of barriers to physical education for Christian and Muslim girls attending comprehensive secondary schools in the UK. Europ Physic Educat Rev. 2014;20(3):349-366. doi: $10.1177 / 1356336$ X14534358

17.Jeanes R, O' Connor J, Alfrey L. Sport and the resettlement of young people from refugee backgrounds in Australia. J Sport Soc Issue. 2015;39(6):480-500. doi: 10.1177/0193723514558929

18. Spaaij R. Beyond the playing field: Experiences of sport, social capital, and integration among Somalis in Australia. Ethnic Racial Stud. 2012;35(9):1519-1538. doi: 10.1080/01419870.2011.592205

19. Spaaij R, Broerse J, Oxford S, Luguetti C, McLachlan F, McDonald B, et al. Sport, Refugees, and Forced Migration: A Critical Review of the Literature. Front Sports Act Living. 2019;1:47. doi: 10.3389/fspor.2019.00047 pmid: 33344970

20.Flintoff A, Dowling F. 'I just treat them all the same, really': Teachers, whiteness and (anti) racism in physical education. Sport Educat Soc. 2019;24(2):121-133. doi: 10.1080/13573322.2017.1332583

21. Cuevas R, García López L, Olivares J. Sport education model and self-determination theory: An intervention in secondary school children. Kinesiol. 2016;48. doi: 10.26582/k.48.1.15

22. Volozhanin S. The importance of physical culture in education of students. Vestnik Minin Univ. 2018. doi: 10.26795/2307-1281-2018-6-3-6

23. Dugnist P, Milkhin V, Golovin S, Romanova E. Healthy lifestyle in the system of value orientations of youth. Human Health Theory Method Physic Culture Sport. 2017;4(7):3-25.

24. Kryshtanovych M, Bilyk V, Hanushchyn S, Sheremet I, Vasylenko K. Modelling the ways to increase the creativity of psychology students as a basic factor in professional development. Creativ Stud. 2021;14(1):34-50. doi: 10.3846/cs.2021.12571

25. Alfrey L, Burke G, O'Connor J, Hall C. Learning about health through 'intergenerational arts-led pedagogies' in health and physical education: exploring pedagogical possibilities. Sport Educat Soc. 2020:1-16. doi: 10.1080/13573322.2020.1814715

26. Skinner D. Challenges in public health pedagogy. Critical Pub Health. 2019;29:1-4. doi: 10.1080/09581596.2019.1538078 